\title{
LA TOPOGRAFÍA Y EL HIDROPERÍODO: DOS FACTORES QUE CONDICIONAN LA RESTAURACIÓN DE LOS HUMEDALES COSTEROS
}

\author{
Francisco Flores-Verdugo ${ }^{1}$, Patricia Moreno-Casasola ${ }^{2,5}$, Claudia Maricusa Agraz- \\ Hernández ${ }^{3}$, Hugo lópez-Rosas², Daniel Benítez-Pardo ${ }^{4}$ y Ana Cecilia Travieso-Bello²
}

\author{
'Instituto de Ciencias del Mar y Limnología, Unidad Académica Mazatlán, Universidad Nacional \\ Autónoma de México, Av. Joel Montes Camarena s/n, Apdo. Postal 811, Mazatlán 82040, Sinaloa, México. \\ ${ }^{2}$ Instituto de Ecología, A.C., km 2.5 Carretera Antigua a Coatepec No. 351, \\ Congregación El Haya, Xalapa 91070, Veracruz, México. \\ ${ }^{3}$ Centro de Ecología, Pesquerías y Oceanografía del Golfo de México (EPOMEX), Universidad Autónoma de \\ Campeche, Av. Agustín Melgar s/n, Col. Buenavista, Campeche 24030, Campeche, México. \\ ${ }^{4}$ Facultad de Ciencias del Mar, Universidad Autónoma de Sinaloa, Apdo. Postal 610, Mazatlán, Sinaloa, México. \\ ${ }^{5}$ Autor para la correspondencia. Correo-e: patricia.moreno@inecol.edu.mx
}

\begin{abstract}
Resumen: Los humedales costeros conjuntan numerosas comunidades que se establecen a lo largo de gradientes topográficos, donde variaciones en salinidad e inundación resultan en composiciones y dinámicas distintas. Un ejemplo es el perfil topográfico de los humedales de la Laguna La Mancha, Veracruz. La temporalidad y la intensidad de mareas y de flujos de agua dulce (escurrimientos o afloramiento del manto freático) determinan el hidroperíodo, definiendo las condiciones de salinidad y de oxidación/reducción del humedal, así como el tipo de humedal. Su restauración debe tomar en cuenta la microtopografía y su consecuencia inmediata, el hidroperíodo. Se presentan ejemplos de estudios topográficos que definen las especies de mangles que deben usarse para restaurar un humedal o para crear uno a partir de la conformación artificial de hábitats. Se muestra la importancia del hidroperíodo en el establecimiento de plantas nativas de humedales de agua dulce y cómo su modificación favorece la entrada y dominancia de especies invasoras.
\end{abstract}

Palabras clave: invasión biológica, manglar, popal-tular, salinidad, tarquina.

\begin{abstract}
Coastal wetlands are composed of several communities located along topographic gradients, where variations in salinity and flooding result in different floristic compositions and dynamics. The topographic profile in the wetlands north of La Mancha Lagoon, Veracruz, Mexico, exemplifies this variety. The temporality and intensity of tides and freshwater fluxes, or a raise in the water table, determine the hidroperiod, defining the salinity and the soil redox conditions, thus characterizing the type of wetland. Restoration practices should take microtopography as well as the resulting hidroperiod into account. The use of topographic information for selecting the mangrove species to be used in reforestation of altered mangroves and in recently created artificial habitats, is demonstrated here. The relevance of the hidroperiod for the establishment of freshwater native species is also shown, as well as how its modification favors the entry and dominance of invasive species.
\end{abstract}

Key words: biological invasion, freshwater wetlands, mangrove, salinity.

L os humedales costeros agrupan numerosas comunidades que abarcan manglares, marismas, selvas y palmares inundables, popales y tulares, entre otros. Esta gran variedad de composiciones y estructuras forma mosaicos a lo largo de gradientes microtopográficos, donde variaciones en salinidad e inundación resultan en composiciones y dinámicas distintas.
La distribución de los diferentes tipos de humedales costeros, las distintas especies que los componen y su grado de desarrollo están condicionados, en gran medida, por el hidroperíodo y la salinidad del agua intersticial. El hidroperíodo es el patrón resultante de la frecuencia y la duración de inundación de cierta área, lo cual determina las condiciones de oxidación/reducción (Lewis, 1982; Mitsch 
y Gosselink, 2000). El patrón de inundación depende de la frecuencia y la duración de las inundaciones provocadas por las mareas, los ríos y los escurrimientos de la región, así como de las áreas que inundan, de las fluctuaciones del nivel freático y de la acreción (Flores-Verdugo et al., 1995; Rico-Gray y Palacios, 1996; Martínez et al., 1997; AgrazHernández, 1999; Méndez, 2003).

Las condiciones impuestas por el hidroperíodo son muy importantes para el mantenimiento de la estructura y el funcionamiento de estos ecosistemas, debido a que crean condiciones físicas y químicas únicas que afectan varios factores como la anaerobiosis del suelo, la acumulación de materia orgánica, la disponibilidad de nutrientes, la riqueza y composición de especies, y la productividad primaria. Asimismo, el componente biótico modifica tanto la hidrología como la composición química del suelo (Middleton, 1999; Mitsch y Gosselink, 2000). Cuando se modifican las condiciones hidrológicas, aunque sea mínimamente, la biota puede responder con cambios masivos en la composición y la riqueza de especies, así como en la productividad (Mitsch y Gosselink, 2000; Travieso-Bello et al., 2005).

En una misma zona, el hidroperíodo también está relacionado con las pequeñas variaciones en el relieve o topografía. El conocimiento de la microtopografía de los humedales permite determinar la distribución de los diferentes tipos de humedales, las áreas potenciales de restauración, así como la ampliación o creación de nuevas áreas para determinadas especies.

La salinidad es un factor que también ayuda a explicar los patrones de distribución vegetal y es fundamental que se tome en cuenta en la restauración de humedales costeros (Callaway et al., 2001). Depende de la cuña salina, de los niveles de infiltración de agua dulce continental y de la evaporación (Cowardin et al., 1979).

Hoy en día, el impacto que producen las distintas actividades humanas, tanto en la microtopografía como en el hidroperíodo, es otro factor importante a considerar. Entre ellas destaca la ganadería. Se reconoce que el pastoreo del ganado impacta de manera directa, mediante el pisoteo y la compactación del suelo, la herbivoría selectiva de la vegetación y la entrada de nutrientes a través de las excretas (Collins et al., 1998; Travieso-Bello et al., 2005). Frecuentemente esta actividad trae aparejada la modificación del hidroperíodo al elevar artificialmente el nivel del suelo, o bien al canalizar el agua para desecar el humedal (Travieso-Bello et al., 2005), obteniéndose así mejores rendimientos de los pastos.

Existen diversas situaciones en las que se han detectado mortalidades masivas de manglar por cambios en su patrón hidrológico producidos por agentes externos al ecosistema, como resultado indirecto de actividades humanas. En este sentido, destacan la Ciénaga Grande de Santa Marta (Caribe colombiano) y Agua Brava (Nayarit), donde se han visto afectadas 30,000 y 8,300 ha de manglar, respectivamente, en el primer caso por la desviación de un río y en el segundo por la apertura de una boca artificial. En ambas situaciones los programas de reforestación están condenados al fracaso si no se tratan de restablecer, al menos parcialmente, las condiciones hidrológicas.

En general, los trabajos de restauración de manglar se han enfocado principalmente a la re forestación y recientemente a la restauración de la hidrología ori ginal. Las áreas reforestadas de manglar han sido aquellas directamente perturbadas por actividades extractivas como la explotación maderera y la elab oración de carbón, o bien el incremento de la fronteraagropecuaria sobre zonas de manglar. En estos casos, la re forestación directa con propágulos es factible cuando las condiciones ambientales no han sido modificadas. La re fo restación con plántulas de vive ro tiene la ventaja de dar una mayor probabilidad de supervivencia que la siembradirecta (Benítez-Pardo, 2003).

Las experiencias de restauración de humedales de agua dulce, tanto de zonas costeras como tierra adentro, son aún muy escasas en México. Se han desarrollado varios proyectos para crear humedales en zonas donde previamente no existían, o bien éstos se han modificado para utilizarlos como plantas de tratamiento de aguas residuales. En México se está impulsando la construcción de humedales de tule (Typha spp.) como humedales seminaturales para el tratamiento de aguas residuales. Existen experiencias en Cucuchucho (Michoacán), a cargo del Instituto Mexicano de Tecnología del Agua, en el Municipio de Santa Cruz Quilehtla, Tlaxcala (Jhabvala, 1998) y en Orizaba por la planta cementera APASCO. Esta última ya tiene varios años en función. En las zonas costeras, en el estado de Quintana Roo, en sitios como Akumal y algunos desarrollos turísticos en la Costa Maya (Molina et al., 1998) se están utilizando humedales artificiales para el tratamiento de aguas de deshecho. Estas experiencias son importantes en la medida en que el diseño para su construcción permite evaluar y poner a prueba los distintos componentes físicos, químicos y biológicos que conforman los humedales.

La hidrología es una de las variables más importantes para la restauración de los humedales costeros y para el diseño de humedales seminaturales. Las condiciones hidrológicas adecuadas permitirán un buen funcionamiento biológico y químico. Las condiciones hidrológicas dependen a su vez del clima, de los patrones estacionales de entrada y salida de agua hacia y desde el humedal, de las mareas (en aquellos que reciben entradas de esta fuente de agua) y de las fluctuaciones del manto freático (Mitsch y Gosselink, 2000). Es decir, una buena parte del funcionamiento hidrológico del humedal depende del hidroperíodo. Al mismo tiempo, éste está condicionado, en parte, por la microtopografía del relieve donde se ubica el humedal. Cuando el diseño hidrológico no es el adecuado, el humedal no funciona (D’Avanzo, 1989). 


\section{Importancia de los humedales}

Los humedales costeros son muy importantes para la biodiversidad de las regiones tropicales y subtropicales del mundo (Field, 1996). En particular, la alta productividad de los manglares hace que sean fundamentales como hábitat de apoyo a las pesquerías, de las que obtienen su sustento numerosas comunidades humanas. Un gran número de especies marinas dependen de los manglares como zona de crianza y alimentación para alevines y larvas de moluscos y crustáceos. El camarón, conocido como el "oro de agua", es la principal fuente de ingresos de la mayoría de los pescadores de las lagunas y mar abierto de regiones tropicales (Martusobroto y Naamin, 1977). La cantidad de camarón guarda una relación directa con la extensión de los manglares. Turner (1991) ofreció un ejemplo muy claro con el camarón Litopenaeus vannamei. Los estados larvarios y juveniles de esta especie se dirigen a las lagunas costeras donde se alimentan hasta las etapas de pre-adultos $\mathrm{y}$ adultos antes de salir al mar a desovar. Este mismo autor estimó una pérdida anual de aproximadamente $800 \mathrm{~kg}$ de pescado y camarón por cada hectárea de manglar destruido. Recientemente se ha encontrado que la ictiofauna de barreras de coral depende de la presencia de manglares. La biomasa de las poblaciones de pez lora (Scarus perrico), especie característica de barreras de coral de importancia pesquera, es más del doble cuando hay presencia de manglares (Mumby et al., 2004).

Moreno-Casasola et al. (2002) observaron una fuerte correlación positiva y significativa entre la captura pesquera y la superficie de las cuencas en el estado de Veracruz, por lo que aparentemente dicha captura está determinada, de manera importante, por la superficie que comprende cada región hidrológica. Es decir, la magnitud, la temporalidad y la calidad de la descarga fluvial en las cuencas tienen un efecto directo sobre la geomorfología y la vegetación costera, así como sobre la cantidad y persistencia de los recursos pesqueros estatales. En este sentido, es importante reconocer que, con frecuencia, la alta productividad de las lagunas costeras depende no solamente de los aportes de los manglares, sino también de los humedales de agua dulce de las tierras bajas que rodean a los manglares y que constituyen la transición hacia terrenos no inundables.

A nivel mundial, se estima una destrucción aproximada de $35 \%$ de los manglares en los últimos 20 años $(1.75 \%$ anual; Blasco et al., 2001). Con aproximadamente 660,000 ha, México ocupa el sexto lugar en el mundo en superficie cubierta de manglar, ubicándose por arriba de la mayoría de los países de África y América, excepto Cuba y Brasil (Flores-Verdugo, 1989; Suman, 1994). Sin embargo, presenta elevadas tasas de destrucción de estos ecosistemas a nivel regional, como en Agua Brava (Nayarit) con más de 8,300 ha destruidas por el cambio hidrológico causado por una boca artificial en la década de 1970 (Kovacs et al., 2001), por la camaronicultura en los estados de Sinaloa y Nayarit y, en alguna época, por el desarrollo petrolero y ganadero en los estados de Veracruz, Tabasco y Campeche. Ahora hay que añadir que la modificación a la Norma Oficial Mexicana NOM 022-SEMARNAT-2003 especificación 4.43 (DOF con fecha de 7 de mayo de 2004) ha creado incertidumbre sobre su aplicabilidad para la conservación de los manglares. Esta modificación permite el cambio del manglar para otro uso de suelo (incompatible con sus funciones ambientales) a cambio de una compensación ambiental por medio de una restauración o c reación de nuevos sitios de manglar. Existe polémica con respecto a que la compensación con manglar bajo el criterio de "pérdida neta cero" sea equivalente en sus funciones ambientales al manglar ori ginal o que el programa de compensación tenga éxito. El $91 \%$ de los manglares plantados en la bahía de Naples (Florida) como medida de compensación han dejado de existir en los últimos cinco años. Se han observado patrones similares de alta mortalidad en dive rsas partes del mundo (Florida Newsletters Inc., enero 20, 2006; Lewis, 2005). Desafortunadamente, en México no se tiene aún una evaluación de la pérdida de superficie que han sufrido los humedales de agua dulce y las estimaciones para manglares muestran valores contradictorios. Algunos autores suponen una pérdida de $12 \%$ y ot ros de 65\% en los últimos 20 años (Agraz-Hernández et al., 2001).

Algunos países concientes de la importancia de los manglares, en particular del sureste asiático, han instrumentado programas de reforestación de manglares con el propósito de mejorar la producción pesquera o de proteger sus costas del efecto de ciclones y tormentas tropicales (Siddiqi y Khan, 1996). En países de América Latina, como Colombia, Cuba y Panamá, se han realizado diversos esfuerzos para reforestar con manglares (Field, 1996; Sánchez-Páez et al., 1998). En México los proyectos de reforestación, de restauración o de manejo sustentable de manglares son escasos o están limitados a un nivel experimental o en informes de baja difusión. Sin embargo, se han realizado o están en proceso algunos esfuerzos en las costas de la Península de Yucatán, Nayarit, Sinaloa, Colima, Chiapas, Guerrero, Baja California Sur y probablemente otros estados, realizados por agencias gubernamentales, agencias no gubernamentales, el sector social, instituciones educativas y de investigación, y por la iniciativa privada a exigencia de instancias gubernamentales (AgrazHernández, 1999; Reyes-Chargoy y Tovilla-Hernández, 2002; Valdez-Hernández, 2002; Benítez-Pardo, 2003).

El objetivo del presente trabajo es demostrar la importancia de la recuperación del hidroperíodo y de la microtopografía para la restauración de humedales costeros, utilizando varios ejemplos. Asimismo, se describen las principales consideraciones ambientales para llevar a cabo un 
proyecto de reforestación, restauración y creación (forestación) de manglares utilizando algunos casos de México.

\section{Heterogeneidad de humedales costeros a lo largo de un gradiente topográfico}

La caracterización de la microtopografía de los humedales permite determinar la distribución de los diferentes tipos de humedales, las áreas potenciales de restauración, así como la ampliación o creación de nuevas áreas para determinado tipo de humedal (Lewis, 1982). La metodología para caracterizar la microtopografía puede variar desde la manguera de nivel hasta el teodolito; los detalles de estas metodologías son descritos por García-Márquez (1984).

En la figura 1 se muestra el perfil de vegetación y el perfil topográfico de un conjunto de humedales de la zona norte de la Laguna La Mancha (centro de Veracruz) realizado con una manguera de nivel, en dirección S-N. El perfil se localiza sobre una misma unidad de paisaje: depresión tectónica-abrasiva, formada por depósitos aluviales y lacuno-palustres, con suelos del tipo gleysol móllico e histosol fíbrico (Priego-Santander et al., 2003).

La vegetación sobre este gradiente (figura 1) está formada por:

1 Manglar dominado por Rhizophora mangle L.

2 Manglar dominado por Avicennia germinans (L.) L. y Laguncularia racemosa (L.) C.F.Gaertn.

3 Tular casi monodominante de Typha domingensis Pers.

4 Popal formado por plantas herbáceas emergentes enraizadas, de hojas anchas, destacando la presencia de Sagittaria lancifolia L., Pontederia sagittata C.Presl, Hydrocotyle umbellata L. y algunas ciperáceas (LópezRosas et al., 2005).

5 Potre ro inundable abandonado donde se sustituyó la vegetación natural por comunidades monodominantes con la especie exótica de origen africano Echinochloa pyramidalis (Lam.) Hitchc. et Chase (López-Rosas et

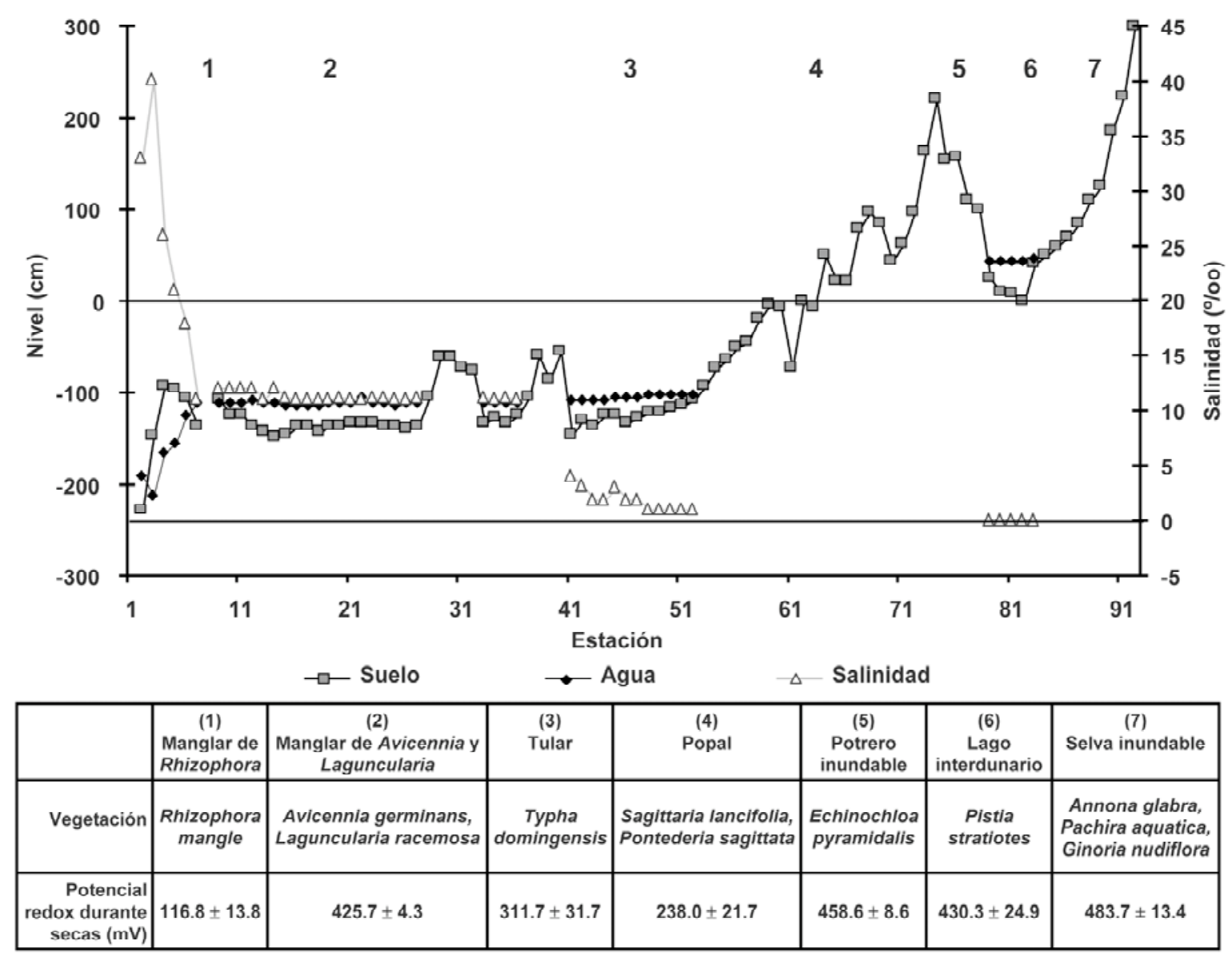

Figura 1. Perfil topográfico y de vegetación a lo largo de un humedal al norte de la laguna La Mancha, Veracruz, México. Se muestra el nivel del agua, del suelo y la salinidad a lo largo de las distintas comunidades del transecto. El potencial redox se midió en una época en que el lago interdunario estaba completamente seco. El corte en el perfil muestra un camino que corta el humedal y que conecta ambos lados mediante un tubo. 
al., 2005; Travieso-Bello et al., 2005).

6 Vegetación flotante de Pistia stratiotes L. en un lago interdunario, cuya inundación depende del manto freático (Yetter, 2004).

7 Selva caducifolia inundable dominada por Annona glabra L. y Pachira aquatica Aubl. (Infante, 2004).

El eje vertical del perfil muestra una variación topográfica de aproximadamente $5 \mathrm{~m}$ (figura 1). Asimismo, se observa un marcado desnivel del agua del lago interdunario (comunidad 6 en el perfil de la figura 1) con respecto a los manglares (comunidades 1 y 2); incluso se midió un desnivel del agua de $4 \mathrm{~cm}$ del tular (comunidad 3 ) hacia los manglares ( 1 y 2). Cambios en la topografía menores de 10 $\mathrm{cm}$ (microtopografía) dan lugar a distintos tipos de comunidades de humedales (figura 1). Los cambios en la topografía se reflejan en la hidrología y en las condiciones de oxidación/reducción del suelo. El potencial redox del suelo (medido en $\mathrm{mV}$ ) es un indicador de las condiciones de anaerobiosis a las que están sujetas las estructuras vegetales subterráneas, así como de la profundidad y temporalidad de la inundación en humedales (Patrick et al., 1996). Los valores de potencial redox obtenidos en cada comunidad van desde ligeramente reducidos (promedio de $116.8 \mathrm{mV}$ en el manglar de Rhizophora) hasta completamente oxidados (promedio de $483.7 \mathrm{mV}$ en la selva inundable), lo que demuestra que variaciones microtopográficas son suficientes para cambiar el ambiente subteráneo donde se establecen las plantas de humedales.

Otro factor asociado con la diferenciación de comunidades vegetales de humedales es la salinidad, que a su vez está asociada con la influencia de las mareas y la cercanía del humedal al mar. La salinidad presente en el agua superficial a lo largo del gradiente estudiado oscila entre 0 y $45 \%$. La salinidad más alta se presenta en los manglares, pero enseguida ésta disminuye hasta menos de 5\%o en los demás humedales del gradiente (humedales dulceacuícolas u oligosalinos, figura 1). El agua intersticial extraída de la zona de raíces, a $15 \mathrm{~cm}$ de profundidad (metodología de McKee et al., 1988) tiene los siguientes promedios ( \pm 1 error estándar) de salinidad: selva inundable de Annona glab ra $1.2 \pm 0.3 \%$, popal de Sagittaria lanci folia $0.4 \pm 0.1 \%$, tular de Typha domingensis $0.8 \pm 0.3 \%$, y pastizal de Echinochloa pyramidalis $0.8 \pm 0.2 \%$. En ninguno de estos humedales la salinidad del agua intersticial es mayor de $1.5 \%$, mientras que en los manglares los valores varían entre $1.8 \pm 0.2 \%$ y $18.7 \pm 11.1 \%$ (H. LópezRosas, datos no publicados).

El gradiente de la figura 1 muestra que las comunidades en ambos extremos -manglares, selva inundable y laguna interdunaria- se diferencian claramente por cambios en la topografía, en la salinidad, o en ambas. Sin embargo, las comunidades ubicadas en el centro del gradiente se diferencian principalmente por su composición florística. Por ello, en la época de lluvias se realizó un muestreo de vegetación y de parámetros fisicoquímicos en la zona de tular-popalpotrero inundable, ubicada en una posición intermedia del gradiente topográfico. El muestreo consistió en trazar cinco transectos en dirección E-O a lo largo del humedal. Dentro de cada transecto se escogieron al azar cuatro puntos en los que se ubicó un cuadro de $1 \mathrm{~m} \times 1 \mathrm{~m}$. En cada cuadro se estimó la cobertura porcentual de cada especie y la topografía (con manguera de nivel), la densidad aparente y la humedad relativa del suelo, la conductividad eléctrica del agua intersticial y la profundidad de la inundación. De los 20 cuadros muestreados se escogieron 10 al azar: cinco con Echinochloa pyramidalis (con coberturas mayores de 80\%) y cinco sin esta especie. Con los datos de estos 10 cuadros se realizó un análisis canónico de correspondencia (ACC) para relacionar los parámetros abióticos con la distribución de estos dos tipos de vegetación (figura 2). Se utilizó el programa PC-ORD para Windows (McCune y Mefford, 1999).

Los cuadros de vegetación dominados por E. pyrami dalis se ubicaron del lado izquierdo de la ordenación (rep resentados con rombos en la figura 2). Estos cuadros son pobres en especies (máximo seis) y se ubican en áreas elevadas del humedal (topografía entre 4.6 y 4.8 m s.n.m.), con suelos compactos (densidad aparente entre 0.44 y 1.49 $\left.\mathrm{g} \mathrm{cm}^{-3}\right)$, conductividad eléctrica alta $\left(1.1 \mathrm{a} 2.0 \mathrm{mS} \mathrm{cm} \mathrm{cm}^{-1}\right.$, bajo nivel de inundación $(-17 \mathrm{a} 10 \mathrm{~cm})$ y baja humedad del suelo (46.9 a 61.7\%). Los cuadros sin E. pyramidalis (representados con círculos en el lado derecho de la figura 2) están dominados por las especies nativas Sagittaria lan cifolia, Typha domingensis y el helecho Achrostichum aureum L., entre otras. Estos cuadros tienen una mayor riqueza de especies (12 especies en total) que los cuadros dominados por la gramínea. Estos cuadros están ubicados en áreas bajas del humedal (topografía entre 4.5 y $4.6 \mathrm{~m}$ s.n.m.; sólo un cuadro, dominado por A. aureum alcanzó un nivel de 4.8 m s.n.m.), con suelos porosos (densidad aparente entre 0.17 y $\left.0.37 \mathrm{~g} \mathrm{~cm}^{-3}\right)$, conductividad eléctrica baja $\left(0.6\right.$ a $\left.1.4 \mathrm{mS} \mathrm{cm} \mathrm{cm}^{-1}\right)$, inundación alta $(5 \mathrm{a} 17 \mathrm{~cm})$ y alta humedad del suelo (59.2 al 68.4\%).

\section{La microtopografía, factor determinante en el establecimiento de especies de humedales}

Los cambios de hidroperíodo pueden inducir la presencia de especies exóticas. Esto es favorecido frecuentemente por la actividad ganadera. En la misma zona donde se realizó el transecto, se eligió un área rectangular de $11.5 \mathrm{~m} \times$ $6.7 \mathrm{~m}$, caracterizada por la dominancia de la gramínea invasora Echinochloa pyramidalis. En esta área se cortó, a nivel del suelo, toda la vegetación y posteriormente se marcaron 60 cuadros de $0.7 \mathrm{~m} \times 0.7 \mathrm{~m}$ cada uno, separados entre sí por un espacio de $0.5 \mathrm{~m}$. Los cuadros se distribuyeron en 10 hileras de seis cuadros cada una. A cada cuadro se le asignó al azar uno de los siguientes tratamientos: (1) hidroperíodo seco: se rellenó con tierra del humedal hasta lograr una 


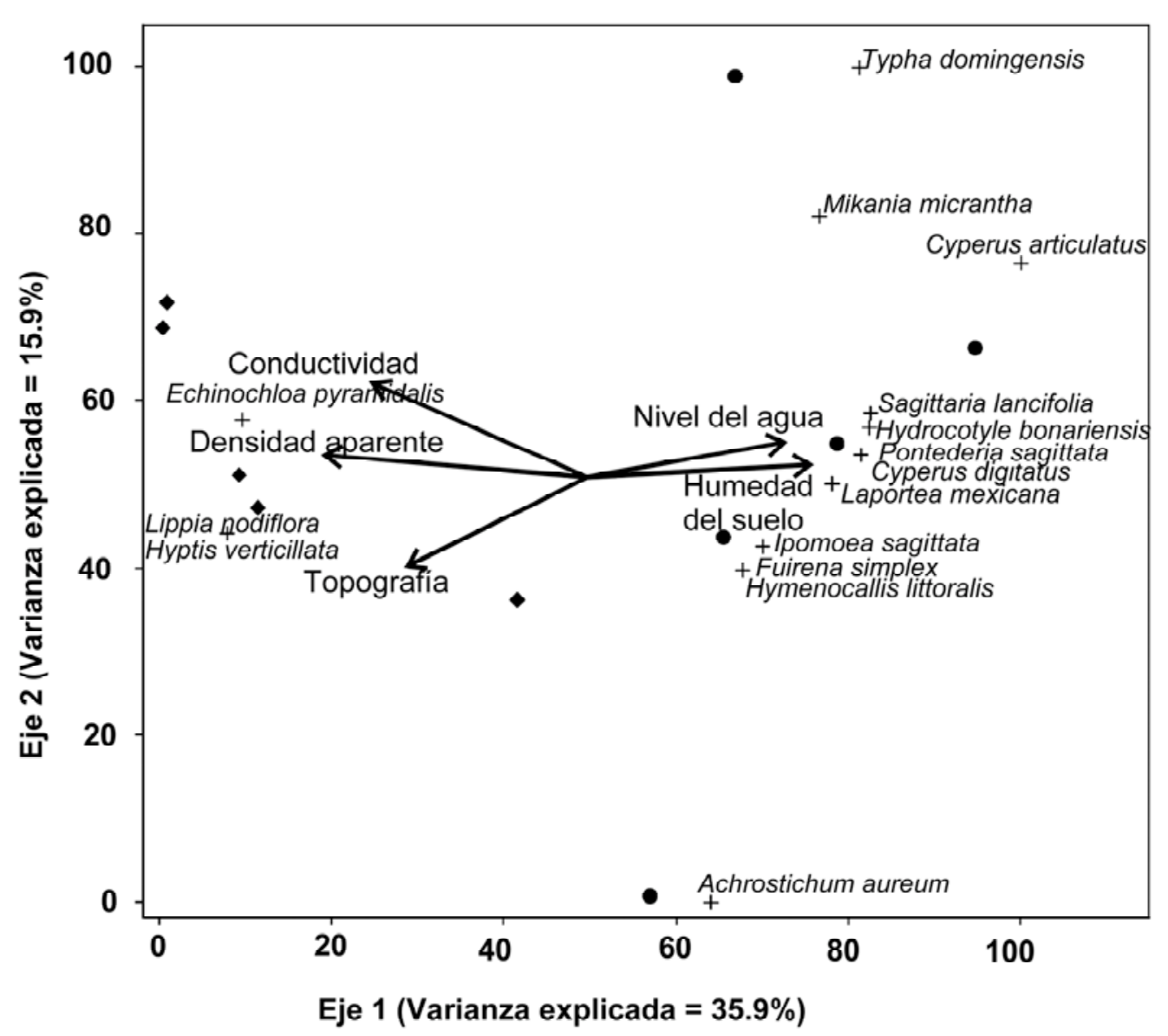

Figura 2. Análisis Canónico de Correspondencia (ACC) de cuadros de vegetación del humedal de agua dulce. Los rombos representan cuadros dominados por Echinochloa pyramidalis. Los círculos representan cuadros sin esta especie. Los parámetros fisicoquímicos están representados por vectores.

altura de $30 \mathrm{~cm}$ sobre el nivel del suelo; (2) hidroperíodo inundado: se excavó hasta lograr una profundidad de $40 \mathrm{~cm}$ bajo el nivel del suelo; (3) hidroperíodo del humedal: no se modificó el nivel del suelo.

Periódicamente se realizaron muestreos de la cobertura de la vegetación. Se presentan los resultados a los 2 y 19 meses después de iniciado el experimento. Para el primer muestreo el objetivo fue evaluar las primeras especies que crecieron en los diferentes tratamientos. Con el segundo muestreo se determinaron las especies capaces de establecerse y dominar en los diferentes niveles de hidroperíodo. Los datos de cada muestreo se analizaron usando un Análisis de Componentes Principales (ACP), con el programa PC-ORD (McCune y Mefford, 1999), para determinar la distribución de especies con respecto a cada uno de los tratamientos.

A los dos meses del tratamiento se tuvieron los resultados que se describen a continuación. Los cuadros con el tratamiento hidroperíodo seco (rombos) se distribuyeron del lado izquierdo de la ordenación (figura 3a), y se carac- terizaron por el crecimiento de plántulas de Pontederia sagittata y diferentes ciperáceas. Los cuadros de vegetación con el tratamiento hidroperíodo del humedal (representados con círculos) se ubicaron del lado derecho de la ordenación; estos cuadros se caracterizaron por la dominancia de Sagittaria lancifolia o Echinochloa pyramidalis. En los cuadros con el tratamiento hidroperíodo inundado (triángulos) hubo un establecimiento mínimo de plantas, por lo que estos cuadros quedaron ubicados en una zona central de la ordenación (figura 3a) y muchos de ellos carecían de vegetación.

Pasados 19 meses de iniciado el experimento, los cuadros con los tratamientos hidroperíodo seco e hidroperío do del humedal se ubicaron del lado izquierdo de la ordenación (figura $3 \mathrm{~b}$ ). Las especies que se establecieron en estos cuadros fueron Echinochloa pyramidalis como especie dominante, seguida por la enredadera Ipomoea sagittata Poir. Los cuadros con hidroperíodo inundado se ubicaron en el lado derecho de la ordenación y se caracterizaron por la dominancia de Sagittaria lancifolia (figura 


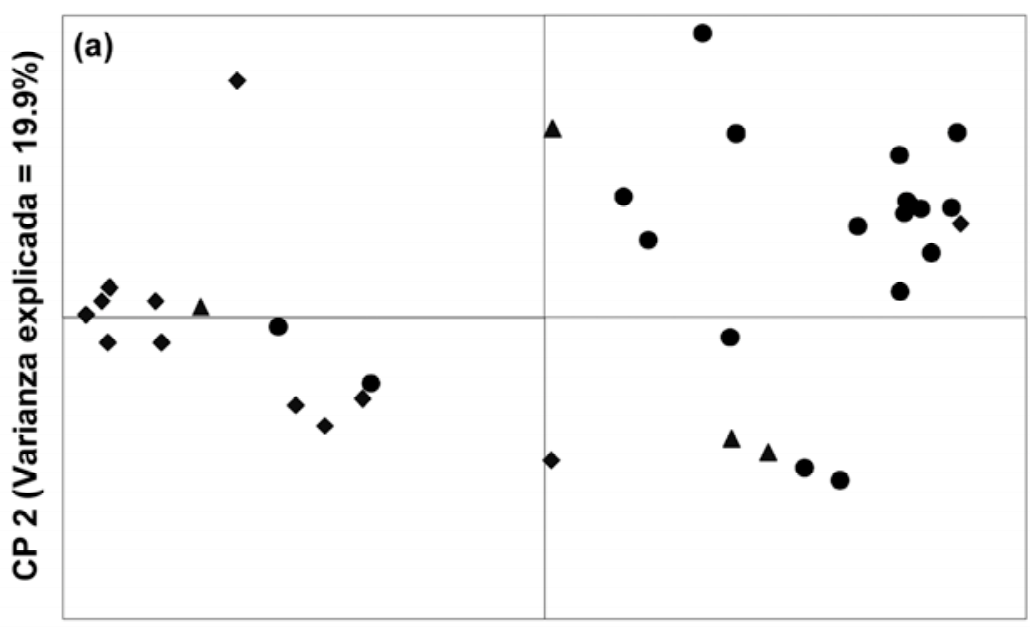

CP 1 (Varianza explicada $=63.6 \%)$

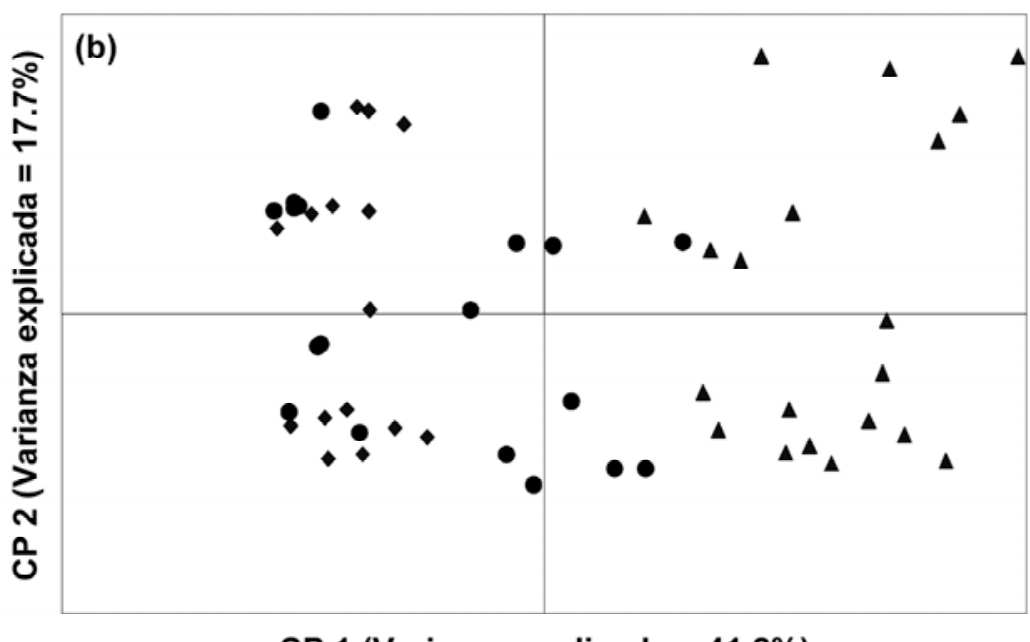

CP 1 (Varianza explicada $=\mathbf{4 1 . 2} \%)$

Figura 3. Análisis de Componentes Principales (ACP) de cuadros experimentales en el humedal de agua dulce. Se presentan los resultados de dos muestreos a los dos (a) y 19 (b) meses desde el inicio del experimento. Los rombos representan a los cuadros con el tratamiento hidroperíodo seco; los triángulos representan a los cuadros con el tratamiento hidroperíodo inundado; los círculos representan a los cuadros con el tratamiento hidroperíodo del humedal.

3b). Especies como Hydrocotyle bonariensis Lam. y la enredadera Mikania micrantha Kunth estuvieron presentes en casi todos los cuadros.

Como ya se mencionó, la frecuencia y el periodo de inundación también son factores determinantes para la ausencia o presencia de los manglares, y las diferentes especies de mangle tienen distintas preferencias de inundación. La presencia de una u otra especie, así como su extensión en un sitio determinado, están definidas por pocos centímetros de diferencia topográfica $(<90 \mathrm{~cm})$. Agraz-Hernández (1999) reportó una clara zonación entre las diferentes especies de mangle con respecto al nivel de las mareas y la salinidad intersticial en el Estero de Urías (Mazatlán, Sinaloa) (figura 4). Resultados similares fueron obtenidos por Flores-Verdugo et al. (1995) en Boca Cegada, Nayarit, donde la diferencia entre la presencia de mangle negro (Avicennia germinans) y su ausencia en una marisma es de 2 a $7 \mathrm{~cm}$ (cuadro 1; figura 5). En el manglar de Arroyo Seco, en Jalisco, Méndez (2003) no detectó correlación significativa entre la altura de los árboles y la salinidad del manto freático, pero sí encontró una correlación positiva significativa entre la altura y la profundidad del manto freático. Tampoco encontró una correlación significativa entre la salinidad del manto freático y la cobertura de los árboles vivos, aunque sí significativa y positiva con la cobertura de los árboles muertos, mostrando que éste es un factor determinante en la supervivencia de las especies de mangle. Las gráficas de dispersión que presenta para 


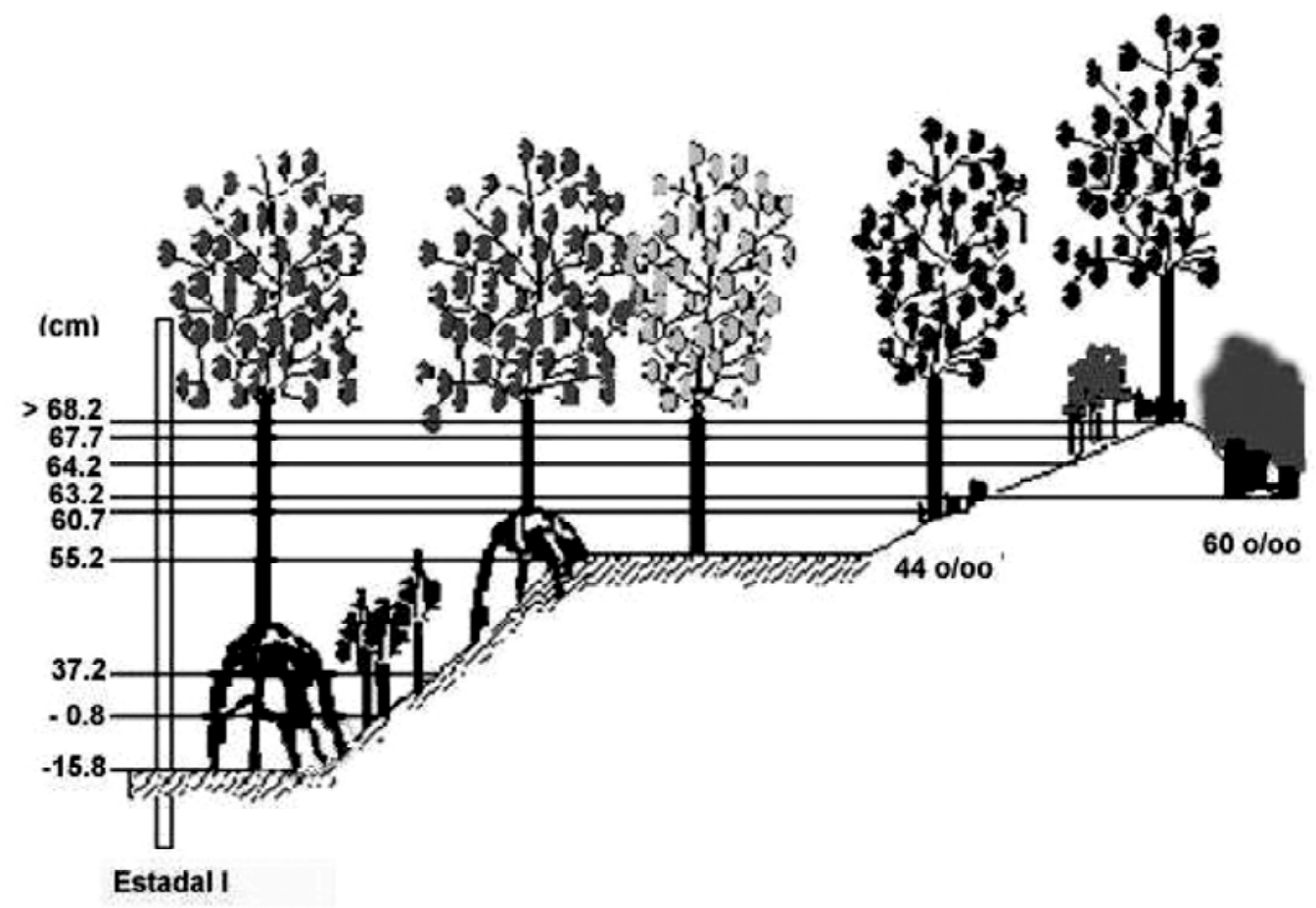

Figura 4. Zonación de formas de crecimiento (árboles, arbustos) y de estadios (plántulas, adultos) de mangle en un gradiente topográfico con respecto al nivel medio del mar (NMM, ver cuadro 1) y a la salinidad intersticial en el Estero de Urías, Sinaloa. \%o corresponde a los valores de salinidad intersticial obtenidos (Agraz-Hernández, 1999).

esta zona muestran una tendencia a incrementare la salinidad del agua conforme aumenta la profundidad del manto freático.

La salinidad intersticial es otro factor que influye en la zonación y el grado de desarrollo de los manglares. La salinidad intersticial corresponde a la salinidad del agua en los sedimentos, y cuando es superior a $70 \%$ provoca la disminución del desarrollo del manglar, llegando a causar su muerte (Cintrón-Molero y Shaeffer-Novelli, 1983). Aunque está ampliamente reconocido que las condiciones óptimas de crecimiento de las distintas especies de mangle, en general, son entre 10 y $20 \%$, algunos autores han encontrado que las diferentes especies tienen distinto grado de tolerancia a salinidades altas, siendo el mangle negro, Avicennia germinans, el más tolerante a las salinidades altas, seguido por el mangle rojo, Rhizophoramangle, y el mangle blanco, Laguncularia racemosa. Esta última especie c rece mejor en salinidades menores a la marina $(<35 \% 0)$. Cuando la salinidad es elevada ( $>70 \%$ ) A. germinans crece como arbusto (Cintrón-Molero y Shaeffer-Novelli, 1983; López-Portillo y Ezcurra, 1989; Flores-Verdugo et al., 1995). Agraz-Hernández (1999) usó un refractómetro para determinar la salinidad del agua intersticial en pozos de 30 $\mathrm{cm}$ de profundidad a lo largo de un transecto microtopográfico de manglar de A. germinans y relacionó este factor con la forma de vida de las plantas. La figura 4 muestra que esta especie crece en forma de arbusto formando matorrales en condiciones hipersalinas, mientras que en el mismo ámbito de distribución topográfica, pero con menor salinidad, las plantas crecen como árboles. Estos resultados también se presentaron en Boca Cegada, Nayarit, donde una salinidad máxima de $60 \%$ permite el desarrollo de un bosque de mangle negro (A. germinans) tipo borde, de $10 \mathrm{~m}$ de altura, que se transforma en tipo matorral con menos de $1 \mathrm{~m}$ de altura en salinidades de $80 \%$, desapareciendo por completo en salinidades mayores de $90 \%$ (figura 5).

\section{El impacto de las actividades humanas en la alteración de la microtopografía}

Las actividades humanas también producen modificaciones ambientales importantes que repercuten no solamente en el hidroperíodo y en la microtopografía, como ya se ha visto, sino también en las características fisicoquímicas del suelo, lo cual añade mayores dificultades a la restauración de una comunidad. En la región de la laguna La Mancha, ubicada en el centro de Veracruz, gran parte de la vegetación de los humedales de agua dulce fue sustituida hace más de cuatro décadas por gramíneas de origen africano [Echinochloa pyramidalis y/o Cynodon plectostachyus (K.Schum.) Pilg.] para pastura de ganado bovino. En algunos casos se redujo el nivel y la intensidad del hidroperíodo debido al relleno y 


\begin{tabular}{|c|c|c|c|c|}
\hline $\begin{array}{l}\text { Unidad } \\
\text { Ambiental }\end{array}$ & $\begin{array}{c}\text { Manglar tipo } \\
\text { borde }\end{array}$ & \begin{tabular}{|c|}
$\begin{array}{c}\text { Manglar tipo } \\
\text { matorral }\end{array}$ \\
\end{tabular} & $\begin{array}{c}\text { Llanura de } \\
\text { halófitas }\end{array}$ & Marisma \\
\hline $\begin{array}{c}\text { Estructura } \\
\text { Forestal }\end{array}$ & $\begin{array}{c}2,050 \mathrm{árb} / \mathrm{ha} \\
22.3 \mathrm{~m}^{2} / \mathrm{ha}\end{array}$ & $\begin{array}{c}40,000 \mathrm{árb} / \mathrm{ha} \\
6.12 \mathrm{~m}^{2} / \mathrm{ha}\end{array}$ & & \\
\hline $\begin{array}{l}\text { Amplitud } \\
\text { Franjas }\end{array}$ & $<30 \mathrm{~m}$ & $5-25 \mathrm{~m}$ & $15-20 \mathrm{~m}$ & $<\dot{b}>80 \mathrm{~m}$ \\
\hline
\end{tabular}

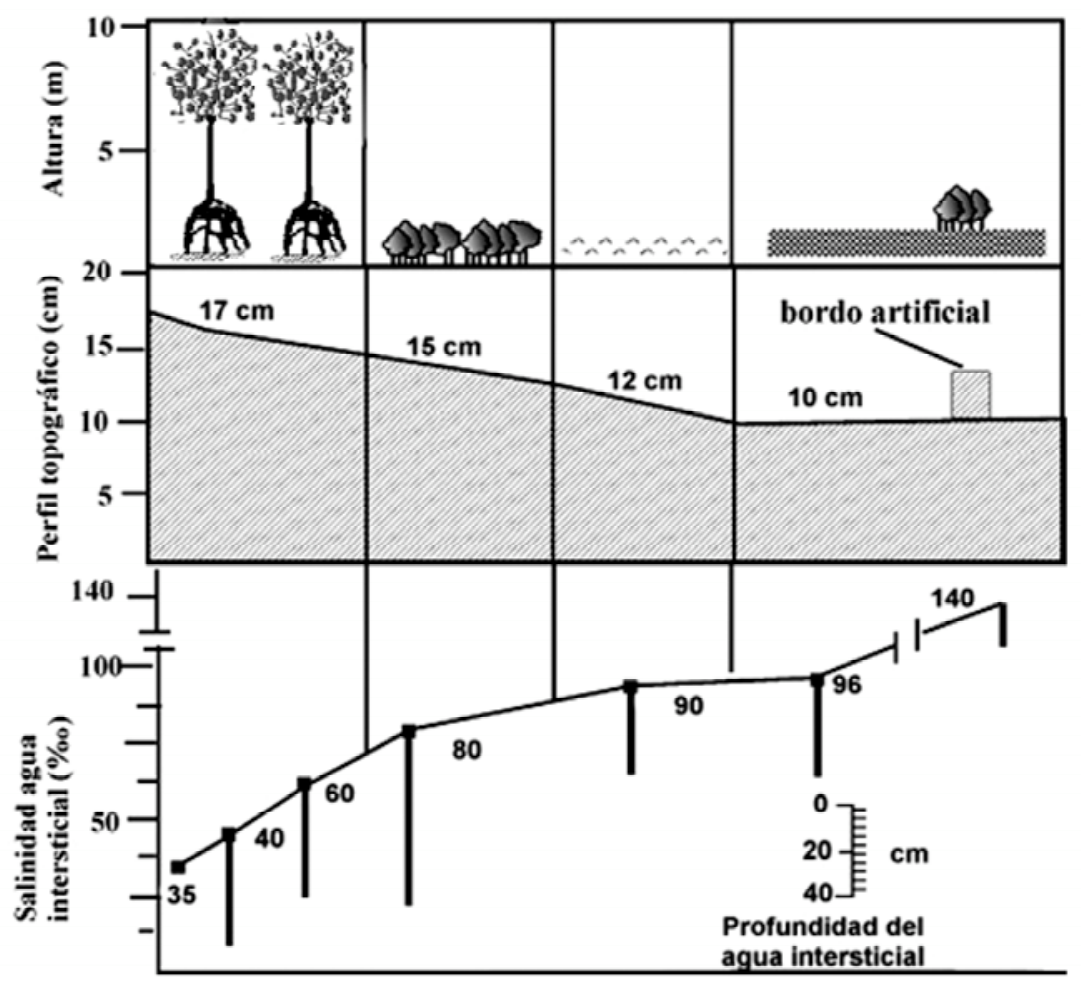

Figura 5. Estructura forestal, distribución topográfica y salinidad intersticial del mangle negro (Avicennia germinans) en una marisma de Boca Cegada, Nayarit.

Cuadro 1. Distribución de especies de mangle con base en la topografía e intervalos de marea con respecto al nivel medio del mar $(\mathrm{nmm}=0)$. Niveles corregidos para Mazatlán, Sinaloa. Tablas de Predicción de Mareas 1998. Instituto de Geofísica UNAM. ISSN01876635 .

\begin{tabular}{lccc}
\hline $\begin{array}{l}\text { Especie } \\
\text { (estadio y forma } \\
\text { de crecimiento) }\end{array}$ & $\begin{array}{c}\text { Intervalo } \\
\text { de mareas } \\
(\mathrm{cm})\end{array}$ & $\begin{array}{c}\text { Amplitud } \\
\text { topográfica } \\
(\mathrm{cm})\end{array}$ \\
\hline $\begin{array}{l}\text { Rhizophora } \\
\text { mangle }\end{array}$ & (árbol adulto) & de -15.8 a 55.2 & 71.0 \\
$\begin{array}{l}\text { Laguncularia } \\
\text { racemosa }\end{array}$ & (árbol adulto) & de 55.2 a ? ? & 0.0 \\
$\begin{array}{l}\text { Avicennia } \\
\text { germinans }\end{array}$ & (árbol adulto) & de 60.7 a $>68.2$ & $>7.5$ \\
$\begin{array}{l}\text { Avicennia } \\
\text { germinans }\end{array}$ & (arbusto adulto) & 63.2 & 3.5 \\
\hline
\end{tabular}

la construcción de pequeños diques en el humedal.

Pa ra ejemplificar esta situación se seleccionaron y cara cterizaron cuatro sitios cercanos entre sí, ubicados sobre una misma geoforma y con una superficie aproximada de 0.5 ha cada uno: un humedal seminatural $(\mathrm{H})$ y tres humedales transformados a potre ros inundables o pastizales. Se denominó PSM al pastizal sin modificaciones del hidroperíodo y bajo pastoreo, PCM1 al pastizal con modificaciones del hidroperíodo y exclusión del ganado, y PCM2 al pastizal con modificaciones del hidroperíodo y bajo pastoreo.

En cada uno de los sitios, al final de la época de secas (mayo de 2001) se tomaron al azar 20 muestras de suelo del horizonte A con una profundidad de $0-20 \mathrm{~cm}$. Con el método del potenciómetro (Jackson, 1964) se determinó el pH de cada muestra en una relación 1:2 (suelo:agua). Se obtuvo el contenido de nitrógeno total $(\mathrm{N})$ con el método de Walkley y Black (1934), el de fósforo extraíble (P) con los métodos micro-Kjeldahl (Bremmer, 1965) y Olsen (Olsen 

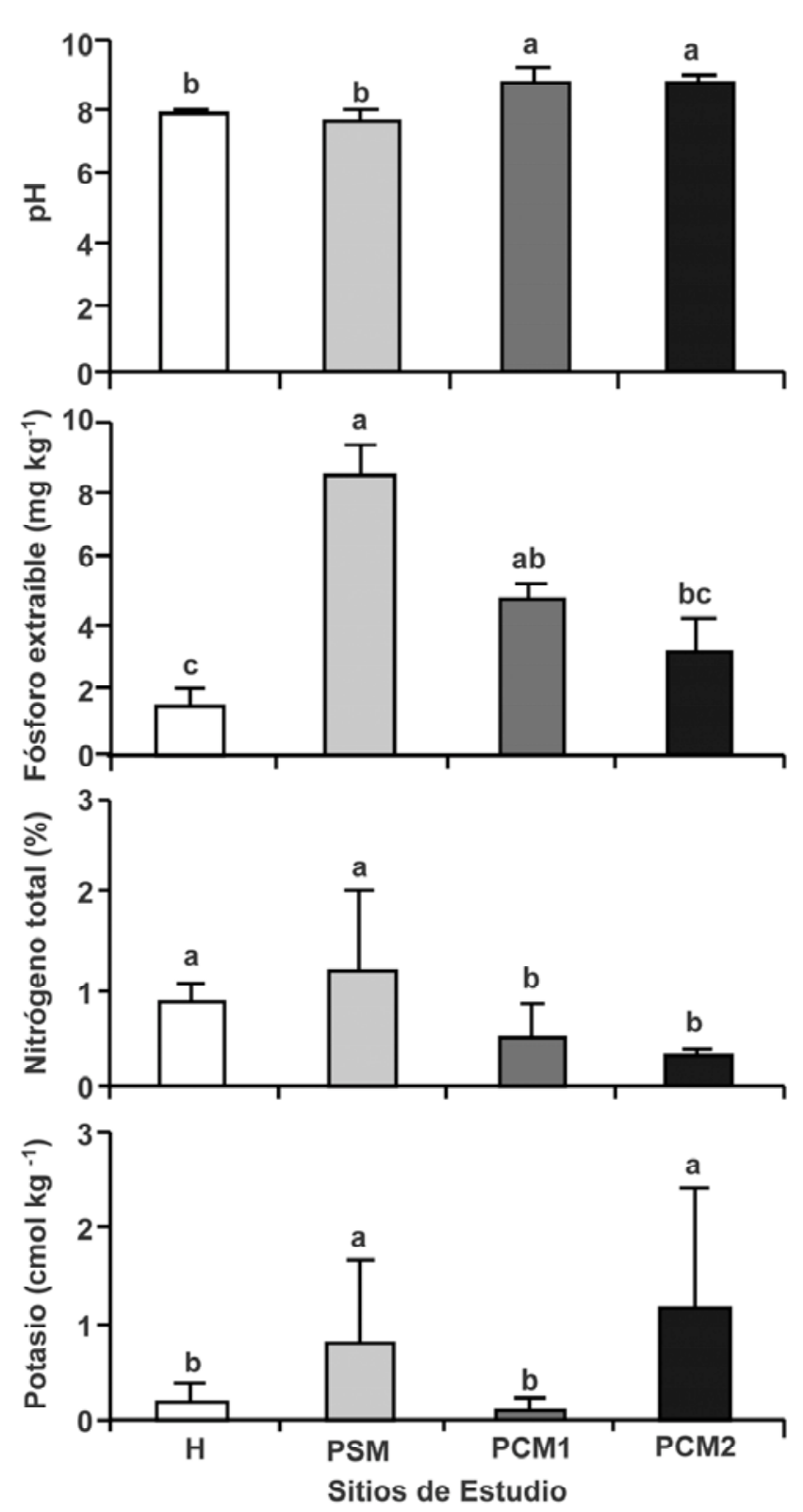

Figura 6. Parámetros químicos del suelo (media + DE) para distintos manejos ganaderos H: humedal seminatural, PSM: Pastizal sin modificación del hidroperíodo y con pastoreo de ganado bovino, PCM1: Pastizal con modificación del hidroperíodo y exclusión del ganado bovino, PCM2: Pastizal con modificación del hidroperíodo y pastoreo de ganado bovino. Letras distintas indican diferencias significativas (con $P<0.05$, ANDEVA de una vía).

y Dean, 1965), y el de ion potasio por fotometría de llama (Chapman, 1965).

Se encontró que al acortarse el período de inundación en humedales trans formados a potreros, se favo rece la mineralización y se reduce la profundidad de la capa orgánica del suelo, lo cual se refleja en la disminución del nitrógeno total (figura 6). Además, aumenta el $\mathrm{pH}$ debido a que se limitan los procesos que acidifican el suelo (Kozlowski, 1984; Mitsch y Gosselink, 2000).

Los humedales transformados a potreros inundables dominados por pastizales aumentan su contenido de fósforo extraíble, probablemente por el aporte de nutrientes de esta actividad y los fertilizantes inorgánicos utilizados en los cultivos de caña de azúcar colindantes. Por lo tanto, cambia la composición química de los humedales naturales, que se caracterizan por una baja disponibilidad de fósforo (Klopatek, 1978; Mitsch y Reeder, 1991). El ion potasio no muestra un patrón asociado al manejo; éste es mayor en los sitios que reciben aportes de agua temporales del estuario La Mancha.

Forestación en tarquinas y en canales artificiales en marismas: una primera etapa en la restauración de manglares

La reforestación ha sido la actividad preponderante para la restauración de manglares, pero en la mayoría de los casos se ha realizado de manera empírica sin tomar en cuenta el hidroperíodo, lo que ha llevado a algunos fracasos o a rendimientos muy bajos. La reforestación se ha hecho utilizando plántulas, al igual que mediante la reproducción vegetativa por acodo aéreo y esquejes. Este tipo de reproducción es factible y con mejores resultados si se realiza en la época de lluvias (Benítez-Pardo et al., 2002).

Existen regiones con elevada sedimentación, que relativamente en poco tiempo llegan a tener los niveles topográficos óptimos (por acreción natural) para el establecimiento de manglares, de forma natural o con plantaciones inducidas (Siddiqi y Khan, 1996). Por otro lado, se pueden inducir acreciones artificiales con ayuda de alguna barrera. Como ejemplo de ello está el uso de neumáticos como barrera artificial que protege a las plántulas, porque se logra reducir la energía erosiva del oleaje y de las corrientes y se propicia la sedimentación de limos y arcillas. El establecimiento de las plántulas de manglar, como en el caso anterior, puede ser de fo rma nat u ral o inducida mediante una forestación de baja densidad. Otra estrategia que se utiliza con relativa frecuencia para inducir acreciones artificiales consiste en la construcción de plataformas o isletas utilizando los materiales de relleno provenientes de dragados $\mathrm{u}$ otras fuentes (tarquinas), los cuales son confinados mediante algún tipo de barrera (tablones o malla geotextil). Otra forma es mediante la formación de canales en las marismas, construyendo en sus márgenes plataformas de mareas para el establecimiento natural o inducido de manglares $\mathrm{u}$ otros humedales.

En el estero de Urías (Sinaloa) en un banco de mareas, se construyeron dos plataformas experimentales dentro de un perímetro de tablones de madera, que fueron rellenadas con sedimento del mismo banco, abarcando una superficie 
de $9 \mathrm{~m}^{2}$ para Rhizophora mangle y $2.5 \mathrm{~m}^{2}$ para Avicennia germinans. Una de las plataformas se rellenó a $30 \mathrm{~cm}$ de altura, lo que correspondió al nivel del suelo de Rhizophora mangle, y la otra, a una altura de $60 \mathrm{~cm}$ comespondiendo al nivel del suelo de Avicennia germinans. La altura de las plataformas se determinó con la ayuda de una manguera de nivel (García-Márquez, 1984). En las plataformas fueron sembradas plántulas de ambas especies en sus correspondientes niveles. El crecimiento de las plántulas que se sembraron en las tarquinas (0.080 a $\left.0.118 \mathrm{~cm} \mathrm{día}^{-1}\right)$ fue significativamente mayor que el de las plántulas control dentro del bosque de manglar (0.0024 a $\left.0.018 \mathrm{~cm} \mathrm{día}^{-1}\right)$. No se detectó diferencia significativa en el crecimiento entre ambas especies de mangle en las plataformas.

Un año después, en el mismo banco de arena, se construyó otra plataforma sin plántulas de mangle. Esta plataforma fue colonizada, de forma natural, por propágulos de mangle blanco (Laguncularia racemosa), logrando una altura superior a $3 \mathrm{~m}$ en cuatro años (F. Flores-Verdugo, datos no publicados).

Actualmente se está desarrollando un proyecto de forestación de tarquinas de dragado (25 ha) en forma de isletas en la laguna de San Ignacio Navachiste (norte de Sinaloa), con el apoyo de un vivero de 20,000 plántulas de mangle (Benítez-Pardo, 2003). En este proyecto se hizo hincapié en la determinación de las áreas susceptibles a forestar con base en los niveles topográficos de dos especies de manglar (rojo y negro) en las tarquinas.

Una vez delimitadas estas áreas, se procedió a reforestar, excluyendo las zonas expuestas al viento y al oleaje. Adicionalmente, se construyeron cercos semilleros en la zona de inundación óptima para el crecimiento de propágulos. Dentro de los cercos se colocaron propágulos para evitar que éstos se dispersaran hacia el exterior de la zona de crecimiento óptimo y para proteger las plántulas del viento y del oleaje refractado.

Los resultados preliminares muestran una buena supervivencia en las tarquinas mayores, donde el oleaje no pasa por arriba de éstas. Las plantas de Rhizophora mangle localizadas dentro del cerco crecieron casi dos veces más rápido $\left(1.2 \mathrm{~cm} \mathrm{mes}^{-1}\right)$ que las plantas ubicadas fuera de los cercos $\left(0.61 \mathrm{~cm} \mathrm{mes}^{-1}\right)$.

Los problemas que se presentaron fueron los siguientes. (1) Las tarquinas aún se encuentran en un proceso de compactación, lo que genera un problema de subsidencia del suelo (hundimiento). Esto ocasionó que los sectores de menor nivel topográfico de las áreas reforestadas se salieran del límite de distribución del manglar. (2) Adicionalmente, por la forma de la tarquina, los sedimentos limo-arcillosos se desplazaron por gravedad hacia las márgenes del islote, formando un cinturón de sedimento limo-arcilloso muy hidratado que da poco sustento a las plántulas y ofrece mucha dificultad para forestar. La parte central de la tarquina concentra los sedimentos arenosos y carbonatados (conchilla). (3) El oleaje redistribuyó el sedimento de las tarquinas, en particular las arenas y los carbonatos, creando una berma de arena que enterró algunas plántulas. (4) En la parte interior de la tarquina en las áreas susceptibles para forestar se presentaron salinidades superiores a $100 \%$ que son intolerables por los mangles. Esto se controló en cierta forma con la construcción de canales interiores. (5) El efecto abrasivo de las macroalgas durante su afloramiento primaveral. En la primavera masas flotantes de macroalgas son transportadas por la corriente y el viento hacia la orilla de las tarquinas y durante la marea alta se acumulan sobre las plántulas de manglar; al bajar la marea, el peso de las macroalgas colapsa las plantas o las llega a desenraizar.

En las marismas los canales con plataformas adyacentes son conocidos como unidades de forestación. En estos canales se acumula material para la construcción de las terazas y se permite la entrada de la marea, lo que reduce la salinidad de los suelos hipersalinos. Esta estrategia sólo se aplica en marismas cuyo nivel del suelo está por abajo del nivel de los manglares (Flores-Verdugo et al., 1995; Agraz-Hernández, 1999). Además de la utilización de los dragados para isletas y plataformas, parte de este material se puede utilizar en las márgenes de los canales dragados y estabilizar el sedimento con plántulas de mangle para aumentar la vida media del canal (Benítez-Pardo, 2003).

En una marisma de Boca Cegada, Nayarit, se construyeron dos bordos artificiales que fueron densamente poblados de forma natural por plántulas de Avicennia germinans; sin embargo, éstas presentaron enanismo a consecuencia de la elevada salinidad de la marisma $(>100 \%$ ). Por ello, se propuso la construcción de pequeños canales de penetración desde una vena de mareas con menor salinidad para disminuir la misma con un mayor recambio de agua, así como para reducir el tiempo de residencia del agua en la marisma (Flores-Verdugo et al., 1995).

La construcción de canales de pequeñas dimensiones o la revitalización hidráulica de las venas de mareas es efectiva para restablecer las condiciones hidrológicas adecuadas para los manglares tipo cuenca o matorral (S án chez-Páez et al., 1998). En Flori d a, la construcción de un puente bloqueó parcialmente la entrada de mareas a una zona de manglares. Al reducirse la fuerza de las mareas en la parte terminal del sistema hidrológico, las venas de $m$ a reas fueron invadidas por los propios mangles, bloqueando el flujo de agua hacia los manglares del interior. Consecuentemente, se procedió a rehabilitar los canales de mareas para la recuperación de los manglares (Lewis, 1982).

Un método relativamente nuevo de acreción artificial diseñado para el mangle rojo, Rhizophora mangle, fue desarrollado por Riley y Salgado-Kent (1999) y consiste en el uso de tubos de PVC de $3.8 \mathrm{~cm}$ (1.5 pulgadas) o de 10.1 $\mathrm{cm}$ (4 pulgadas) de diámetro y de 50 a $70 \mathrm{~cm}$ de longitud 
con una ranura a todo lo largo. Los tubos son rellenados con sedimento hasta la altura correspondiente al suelo del manglar. Este método tiene ventajas adicionales como la de requerir menor cantidad de sedimento que las plataformas, proteger a la plántula de la abrasión por corrientes, oleaje y detritus, de los rayos ultravioletas, de la herbivoría por macroinverteb rados y vertebrados, y estimular su crecimiento vertical. Sin embargo, el uso de PVC ha sido fuertemente cuestionado por no ser biodegradable, por lo que estos autores recomiendan la remoción del PVC una vez que la plántula haya enraizado fuera del tubo.

\section{Consideraciones generales}

Los humedales costeros constituyen humedales de gran importancia, por lo que es fundamental desarrollar metodologías que permitan su restauración y la recuperación de las áreas degradadas. Los datos presentados en este trabajo muestran la distribución de distintos tipos de humedales, incluyendo las comunidades que los reemplazan (potreros inundables) a lo largo de un gradiente topográfico, en el cual las variaciones en el nivel del suelo determinan el hidroperíodo y las diferencias en los valores de oxidación/reducción.

La microtopografía, la influencia de las mareas, así como la presión hidrostática ejercida por los aportes de agua dulce, son factores determinantes en el hidroperíodo. La combinación del hidroperíodo, la salinidad marina y su gradiente de mezcla con el agua dulce y los aportes de materia orgánica de la vegetación acuática, a su vez, determinan los procesos geomicrobianos del sedimento, en función de las condiciones de oxidación y reducción presentes. En particular los pantanos de agua dulce actúan como reservorios de agua dulce (como lo muestra la diferencia de niveles del agua en la figura 1) amortiguando el efecto de las inundaciones en la época de lluvias y liberando agua en la temporada de estiaje.

Por tanto, la restauración de humedales de agua dulce al igual que la de los manglares, requiere de un conocimiento básico del hidroperíodo y de la microtopogafía del humedal, en particular. Los datos mostrados permiten concluir que elevaciones mínimas en la topografía del humedal son suficientes para facilitar la invasión de especies exóticas o ajenas a los humedales, como es el caso de Echinochloa pyramidalis. Este incremento en la topografía también tiene repercusiones en el hidroperíodo del humedal, porque disminuye el nivel de la inundación durante la estación lluviosa y reduce las posibilidades de supervivencia de las especies nativas o por lo menos disminuye su capacidad competitiva frente a otras especies. Finalmente la compactación del suelo en las zonas dominadas por $E$. pyramidalis puede ser resultado del proceso de invasión debido a la alta producción de raíces de esta especie.
La restauración de manglares se puede realizar mediante tres métodos: la reforestación, la restauración hidrológica o la combinación de ambas. Estos métodos requieren de un conocimiento básico del hidroperíodo de la región y éste, a su vez, del régimen de mareas y de la microtopografía. La creación de nuevas áreas de forestación con manglares mediante la acreción artificial debe evitarse en lo posible en bajos de mareas de elevada productividad primaria y secundaria, y de preferencia en zonas perturbadas por asolvamiento intenso o con evidencias de sobrepesca (de bivalvos), en granjas camaronícolas abandonadas y en algunas marismas. Además del hidroperíodo y la salinidad, deben tomarse en cuenta otros factores ambientales para una re fo restación efectiva, como la energía de oleaje, las corrientes y la abrasión por detritus flotante.

Méndez (2003) reporta una zonación de manglares en Jalisco relacionada claramente con el mosaico geomorfológico y con la dinámica espacio-temporal dada por la acreción de sedimentos hacia la laguna. Esto es similar a otros gradientes reportados para manglares, los cuales están condicionados por la topografía, la tex tu ra del suelo y la profundidad del manto freático, lo cual a su vez influye en la salinidad del propio manto y en el grado de i nundación (y de anoxia), y por tanto en el establecimiento y supervivencia de las especies de mangle (LópezPortillo y Ezcurra, 1989). Con frecuencia se utiliza la zonación de las especies de manera empírica para decidir qué especie de mangle utilizar para reforestar o restaurar un parche, ya que es un reflejo de la microtopografía y de la salinidad intersticial. Sin embargo, la dinámica de estos ecosistemas hace necesario contar con información sobre el microrelieve donde se va a restaurar, para asegurar el éxito de la plantación.

Por lo tanto, la restauración de los humedales implica la recuperación no solamente de la estructura y la composición de la vegetación, sino del funcionamiento hidrológico. Implica la recuperación de las entradas y salidas de agua, de la magnitud y temporalidad de la inundación, y de la salinidad acompañante. Pero para ello, lo primero que se necesita es conocer el funcionamiento hidrológico de la gran heterogeneidad ambiental que compone los humedales mexicanos.

Los resultados de este estudio permiten hacer las siguientes recomendaciones finales orientadas a la restauración de humedales costeros. En primer lugar, se deben conocer las modificaciones realizadas en la microtopografía, el hidroperíodo y la salinidad de los humedales, antes de llevar a cabo la restauración, ya que estos factores determinan el tipo de humedal, su composición de especies, su desarrollo, así como su funcionamiento. Asimismo, se recomienda establecer controles cercanos, con los cuales se pueda comparar y usar como mediciones de base para el diseño del trabajo de restauración.

Si sólo se ha reemplazado la vegetación característica de 
los humedales por otro tipo de vegetación o cultivo, puede procederse a la reforestación o a la restauración directa. Sin embargo, si se ha modificado la microtopografía, es posible que esto haya alterado también el hidroperíodo; por tanto, es imprescindible restablecerlos antes de iniciar el trabajo. Para revertir los daños de los ecosistemas invadidos por gramíneas es necesario conocer la biología de las especies invasoras y así poder dirigir los esfuerzos a atacar aquellos rasgos de forma de vida que hacen a estas especies particularmente invasoras en un sitio.

Es importante determinar la salinidad del área a restaurar debido a que este factor determina el tipo de humedal que se establece en un área. Específicamente en el caso del manglar, la salinidad determina la composición de especies. Además, valores altos de salinidad disminuyen el desarrollo de las especies de mangle, las cuales crecen formado un matorral enano o inclusive pueden morir. En estos casos es necesario recuperar la hidrología del manglar.

Finalmente, se recomienda construir canales de pequeñas dimensiones o llevar a cabo la revitalización hidráulica de las venas de marea para reestablecer las condiciones hid roló gicas ap ropiadas y disminuir la salinidad.

\section{Agradecimientos}

Los perfiles topográficos se hicieron con apoyo de los estudiantes del curso de Ecología de Ecosistemas Tropicales, generación 2003, INECOL-LSU-OTS en los humedales de La Mancha y con el apoyo del M. en C. Sergio Rendón, M. en C. Arturo Núñez Pastén y la Biol. Raquel Briseño Dueñas en el Estero de Urías y Marismas de Boca Cegada, Nayarit. Agradecemos a J.R. Hernández Santana, A. Lot, y J. Meave los comentarios hechos al manuscrito, ayudando de manera importante a su mejora.

\section{Literatura citada}

Agraz-Hernández C.M. 1999. Reforestación experimental de manglares en ecosistemas lagunares estuarinos de la costa noroccidental de México. Tesis de Doctorado, Facultad de Ciencias Biológicas, Universidad Autónoma de Nuevo León, Monterrey, $133 \mathrm{pp}$.

Agraz-Hernández C.M., Flores-Verdugo F. y Calvario-Martínez O. 2001. Impacto de la camaronicultura en ecosistemas de manglar y medidas de mitigación. En: Páez-Osuna F. Ed. Camaronicultura y Medio Ambiente, pp. 372-389, Universidad Nacional Autónoma de México y El Colegio de Sinaloa, México, D.F.

Benítez-Pardo D. 2003. Creación de Áreas de Manglares en Islas de Dragados como Apoyo Potencial a las Pesquerías en la Bahía de Navachiste, Sinaloa, México. Universidad Autónoma de Sinaloa y Comisión Nacional de Pesca y Acuacultura, Mazatlán.

Benítez-Pardo D., Flores-Verdugo F. y Valdéz J.L. 2002. Reproducción vegetativa de dos especies arbóreas en un manglar de la costa norte del Pacífico mexicano. Maderas y Bosques 8:57-71.

Blasco F., Aizpuru M. y Gers C. 2001. Depletion of the mangroves of continental Asia. Wetlands Ecology and Management 9:245-256.

Bremmer J.M. 1965. Total nitrogen. En: Black C.A. Ed. Methods of Soil Analysis. Part 2, Agronomy 9, pp. 1149-1178, American Society of Agronomy, Madison, Wisconsin.

Callaway J.C., Sullivan G., Desmond J.S., Williams G.D. y Zedler J.B. 2001. Assessment and monitoring. En: Zedler J.B. Ed. Handbook for Restoring Tidal Wetlands, pp. 271-326, CRC Press, Boca Raton, Florida.

Chapman H.D. 1965. Cation exchange capacity. En: Black C.A. Ed. Methods of Soil Analysis. Part 2, Agronomy 9, pp. 891901, American Society of Agronomy, Madison, Wisconsin.

Cintrón-Molero G. y Schaeffer-Novelli Y. 1983. Introducción a la Ecología del Manglar. Oficina Regional de Ciencia y Tecnología de la Organización de las Naciones Unidas para la Educación, la Ciencia y la Cultura para America Latina y el Caribe - ROSTLAC, Montevideo.

Collins S.L., Knapp A.K., Briggs J.M., Blair J.M. y Steinauer E.M. 1998. Modulation of diversity by grazing and mowing in native tallgrass prairie. Science 280:745-747.

Cowardin L.M., Carter V., Golet F.C. y LaRoe E.T. 1979. Classification of Wetlands and Deepwater Habitats of the United States. United States Fish and Wildlife Service, Washington, D.C.

D' Avanzo C. 1989. Long term evaluation of wetland-creation projects. En: Kusler J.A. y Kentula M.E. Eds. Wetland Creation and Restoration: The Status of the Science, Vol. 1, pp. 75-84, U.S. Envi ronmental Protection Agency, Corvallis, Oregon.

Field C.D. (Ed.) 1996. La Restauración de Ecosistemas de Manglar. Sociedad Internacional para los Ecosistemas de Manglares y Organización Internacional de las Maderas Tropicales, Okinawa.

Flores-Verdugo F. 1989. Algunos aspectos sobre la ecología, uso e importancia de los ecosistemas de manglar. En: Rosa-Vélez J. y González Farías F. Eds. Temas de Oceanografía Biológica en México, pp. 22-56, Universidad Autónoma de Baja California, Ensenada.

Flores-Verdu go F., A graz-Hemández C.M. y Martínez-Cordero F.J. 1995. Programa de reforestación de manglares por el desamollo acuícola de Aquanova-Boca Cegada (Nayarit): Evaluación ecológica integral y medidas de mitigación. Antep royecto. Unidad Mazatlán en Acuicultura y Manejo Ambiental. Informe Final Técnico, Centro de Investigación en Alimentación y Desarrollo y Facultad de Ciencias Biológicas, Universidad Autónoma de Nuevo León, Mazatlán, Sinaloa.

García-Márquez F. 1984. Topografía Aplicada. Concepto, S.A., México, D.F.

Infante D.M. 2004. Germinación y establecimiento de Annona glabra (Annonaceae) y Pachira aquatica (Bombacaceae) en humedales, La Mancha, Actopan. Tesis de Maestría, Instituto de Ecología, A.C., Xalapa, 124 pp.

Jackson M.L. 1964. Análisis Químicos del Suelo. Omega, Barcelona.

Jhabvala F. 1998. La experiencia de la tecnología de pantanos artificiales para el saneamiento de las aguas residuales de Quilehtla, Tlaxcala. En: Olguín E.J., Sánchez G., Galicia S. y 
Hernández E. Comp. Memorias en extenso, Tercer Simposio Internacional de Bioprocesos Más Limpios y Desarrollo Sustentable, pp. 95-101, World Association of Industrial and Technological Research Organizations y Centro Internacional de Tecnologías Limpias y Desarrollo Sustentable, A.C., Instituto de Ecología, A.C., Xalapa.

Klopatek J.M. 1978. Nutrient dynamics of freshwater riverine marshes and the role of emergent macrophytes. En: Good R.E., Whigham D.F. y Simpson R.L. Eds. Freshwater Wetlands: Ecological Processes and Management Potential, pp. 195-216, Academic Press, Nueva York.

Kovacs J.M., Blanco-Moreno M. y Flores-Verdugo F. 2001. A logistic regression model of hurricane impacts in a mangrove forest of the Mexican Pacific. Journal of Coastal Research 17:30-37.

Kozlowski T.T. 1984. Plant responses to flooding of soil. BioScience 34:162-167.

Lewis R.R. 1982. Mangrove forest. En: Lewis R.R. Ed. Creation and Restoration of Coastal Plant Communities, pp. 153-171, CRC Press, Boca Raton, Florida.

Lewis R.R. 2005. Ecological engineering for successful management and restoration of mangrove forests. Ecological Engineering 24:403-418.

López-Portillo J. y Ezcurra E. 1989. Response of three mangroves to salinity in two geoforms. Functional Ecology 3:355-361.

López-Rosas H., Moreno-Casasola P. y Mendelssohn I.A. 2005. Effects of an African grass invasion on vegetation, soil and interstitial water characteristics in a tropical freshwater marsh in La Mancha, Veracruz (Mexico). Journal of Plant Interactions 1:187-195.

Martínez M.L., Moreno-Casasola P. y Vázquez G. 1997. Long term effect of sand movement and inundation by water on tropical coastal sand dune vegetation. Canadian Journal of Botany 75:2005-2014.

Martusobroto P. y Naamin N. 1977. Relation between tidal forest (mangroves) and commercial shrimp production in Indonesia. Marine Resources Indonesia 18:81-85.

McCune B. y Mefford M.J. 1999. Multivariate analysis of ecological data. Versión 4.01. MjM Software, Gleneden Beach, Oregon.

McKee K.L., Mendelssohn I.A. y Hester M.W. 1988. A reexamination of pore water sulfide concentrations and redox potentials near the aerial roots of Rhizophora mangle and Avicennia germinans. American Journal of Botany 75:1352-1359.

Méndez L.A. P. 2003. Fisonomía y estructura de diferentes asociaciones de manglar y su relación con la geomorfología del abanico deltaico de Arroyo Seco. Jalisco. Tesis de Maestría (Biología), Facultad de Ciencias, Universidad Nacional Autónoma de México, México, D.F., 81 pp.

Middleton B.A. 1999. Wetland Restoration, Flood Pulsing and Disturbance Dynamics. John Wiley and Sons, Nueva York.

Mitsch W.J. y Gosselink J.G. 2000. Wetlands. John Wiley and Sons, Nueva York.

Mitsch W.J. y Reeder B.C. 1991. Modeling nutrient retention of a freshwater coastal wetland: Estimating the roles of primary productivity, sedimentation, resuspension and hydrology. Ecological Modelling 54:151-187.

Molina C., Rubinoff P. y Carranza J. 1998. Normas prácticas para el desarrollo turístico de la zona costera de Quintana Roo, México. Amigos de Sian Ka'an, A.C., Centro de Recursos
Costeros y University of Rhode Island, Chetumal.

Moreno-Casasola P., Rojas J.L., Zárate D., Ortiz M.A., LaraDomínguez A.L. y Saavedra T. 2002. Diagnóstico de los manglares de Veracruz: distribución, vínculo con los recursos pesqueros y su problemática. Madera y Bosques 1:61-88.

Mumby P.J., Edwards A.J., Arias-González J.E., Lindeman K.C., Blackwell P.G., Gall A., Gorczynska M.I., Herbona A.R., Pescod C.L., Renken H., Wabnitz C.C. y Llewellyn G. 2004. Mangroves enhance the biomass of coral reef fish communities in the Caribbean. Nature 427:533-536.

Olsen S.R. y Dean L.A. 1965. Phosphorus. En: Black C.A. Ed. Methods of Soil Analysis. Part 2, Agronomy 9, pp. 1035-1049, American Society of Agronomy, Madison, Wisconsin.

Patrick W.H., Gambrell R.P. y Faulkner S.P. 1996. Redox measurements of soils. En: Sparks D.L. Ed. Methods of Soil Analysis, Part 3, Chemical Methods, pp. 1255-1273, Soil Science Society of America y American Society of Agronomy, Madison, Wisconsin.

Priego-Santander A.G., Moreno-Casasola P., Palacio-Prieto J.L., López-Portillo J.A. y Geissert-Kientz D. 2003. Relación entre la heterogeneidad del paisaje y la riqueza de especies de flora en cuencas costeras del estado de Veracruz, México. Boletín del Instituto de Geografía 52:31-52.

Reyes Chargoy M.A. y Tovilla C.H. 2002. Restauración de áreas alteradas de manglar con Rhizophora mangle en la costa de Chiapas. Madera y Bosques 1:103-115.

Rico-Gray V. y Palacios M. 1996. Salinidad y el nivel de agua como factores en la distribución de vegetación en la ciénaga del NW de Campeche, México. Acta Botanica Mexicana 34:53-61.

Riley R.W. y Salgado-Kent C.P. 1999. Riley encased methodology: Principles and processes of mangrove habitat creation and restoration. Mangrove and Saltmarshes 3:207-213.

Sánchez-Páez H., Ulloa-Delgado G.A. y Álvarez-León R. 1998. Hacia la Recuperación de los Manglares del Caribe de Colombia. Ministerio del Medio Ambiente, Asociación Colombiana de Reforestadores y Organización Internacional de las Maderas Tropicales, Bogotá.

Siddiqi N.A. y Khan M.A.S. 1996. Técnicas de plantación para manglares sobre nuevas acreciones en las áreas costeras de Bangladesh. En: Field C. Ed. La Restauración de Ecosistemas de Manglar, pp. 157-175, Sociedad Internacional para los Ecosistemas de Manglares y Organización Internacional de las Maderas Tropicales, Okinawa.

Suman D.O. 1994. El Ecosistema de Manglar en América Latina y la Cuenca del Caribe: Su Manejo y Conservación. Universidad de Miami, Florida y Tinker Foundation, Nueva York.

Travieso-Bello A.C., Moreno-Casasola P. y Campos A. 2005. Efecto de diferentes manejos pecuarios sobre el suelo y la vegetación en humedales transformados a pastizales. Interciencia 30:12-18.

Turner R.E. 1991. Factors affecting the relative abundance of shrimp in Ecuador. En: Olsen S. y Arriaga L. Eds. A Sustainable Shrimp Mariculture Industry for Ecuador, Technical Report Series TR-E-6, pp. 121-139, International Coastal Resources Management Project, Universidad de Rhode Island, Nueva York.

Valdez-Hernández J.I. 2002. Aprovechamiento forestal de manglares en el estado de Nayarit, costa Pacífica de México. 
Madera y Bosques 1:129-145.

Walkley A. y Black T.A. 1934. An examination of the Degtjarett method for determining soil organic matter and a proposed modification of the chromic acid titration method. Soil Science 37:29-38.

Yetter J.C. 2004. Hydrology and geochemistry of freshwater wetlands on the Gulf coast of Veracruz, Mexico. Tesis de
Doctorado, Unive rsidad de Waterloo, Waterloo, Ontario, 168 pp.

Fecha de recepción: 24 de junio de 2005

Versión corregida: 27 de junio de 2006

Aceptado: 26 de octubre de 2006

NOTA: Mientras este artículo estaba en prensa, se promulgó un decreto por el que se adiciona un artículo 60 TER y un segundo párrafo al artículo 99 de la Ley General de Vida Silvestre para proteger el manglar. Fue publicada en el Diario Oficial de la Federación el $1^{\circ}$ de febrero de 2007. 